\title{
Cumulative Contexts of Vulnerability to Intimate Partner Violence Among Women With Disabilities, Elderly Women, and Immigrant Women: Prevalence, Risk Factors, Explanatory Theories, and Prevention
}

\author{
Nathalie Sasseville, Pierre Maurice, Lise Montminy, \\ Ghayda Hassan, and Emilie St-Pierre
}

\begin{abstract}
Some groups of women are more vulnerable to intimate partner violence (IPV) due to particular risks and/or experiences: women with disabilities, elderly women, and immigrant women (DEI). Too often, their reality goes unnoticed, especially for those belonging to more than one of these groups. In this literature review, researchers used an intersectional approach to document the similarities and differences in how DEI women experience IPV, in terms of forms and consequences, as well as related risk factors, explanatory theories, and prevention strategies. Researchers selected 56 articles for review based on the following inclusion criteria: studies on adults living in a situation of IPV, studies on one of the three demographics under study (DEI), studies about one or multiple research questions, and studies based on empirical data relying on research methodology in either French or English. Researchers evaluated each selected article for its quality according to a chart that was specially developed for this review. The results highlight existing "intersections" between these groups to help understand the influence of belonging to more than one vulnerability group on these women's experiences with IPV. The importance to better training social workers and developing policies and programs that target the social determinants of health to prevent IPV experienced by DEI is also discussed.
\end{abstract}

\section{Keywords}

elderly women, immigrant women, women with disabilities, cumulative vulnerabilities, intimate partner violence 
Intimate partner violence (IPV) is a serious public health problem that affects a significant proportion of women across all social classes (World Health Organization, 2013). Certain women, including those with disabilities, elderly women, and immigrant women (DEI), are more vulnerable to IPV (Gouvernement du Québec, 1995). The scientific literature has focused mostly on the issue of IPV that young Western women in a heterosexual relationship experience (Brownridge, 2009). There are so few data on DEI women that their experience with IPV has remained largely unheard (Montminy \& Drouin, 2009; Plummer \& Findley, 2012). This situation contributes to hiding the fact that they experience IPV and perpetuates prejudices according to which IPV concerns solely able-bodied, middle-aged Western women (Brownridge, 2006; Plummer \& Findley, 2012). Furthermore, when the literature does address the situation of DEI women, it generally takes a compartmentalized approach (i.e., a woman with a disability, an elderly woman, or an immigrant woman), overlooking the fact that a same woman may experience several of these contexts simultaneously. In this respect, implemented partnerships with women's shelters confirm that caseworkers are confronted to cumulative contexts of vulnerability to IPV. However, as this is a phenomenon generally unknown, they must work without the required knowledge on the subject.

The purpose of this article is to present the results of a critical literature review concerning the three cumulative contexts of vulnerability to IPV among DEI women. Moreover, by using an intersectional approach, researchers will attempt to identify similarities and distinctions regarding the forms and consequences for DEI women experiencing IPV as well as risk factors, explanatory theories, and prevention strategies 
related to this issue. Thus, this article aims to fill an obvious gap of knowledge in this field.

\section{Figure 1. Cumulative Contexts of Vulnerability to IPV in Groups of DEI Women From an Intersectional Perspective}

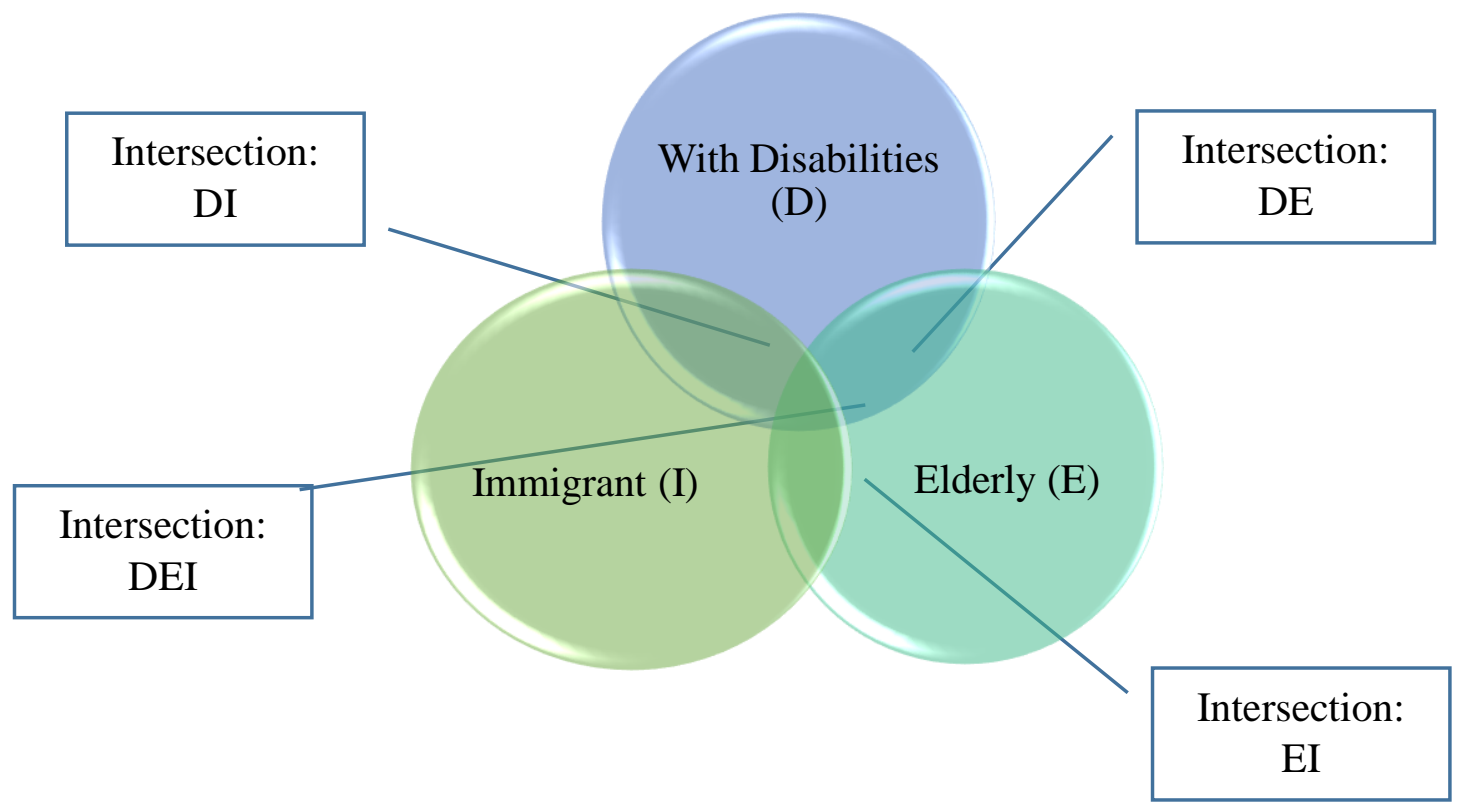

Using Intersectionality to Account for the Contexts of Vulnerability to IPV

The intersectional approach is used to understand and study IPV (Corbeil \& Marchand, 2006; Harper \& Kurtzman, 2014; Oxman-Martinez \& Krane, 2005). In this literature review, researchers conducted a critical analysis of the "intersections" that exist between the three DEI groups to better understand the complexity and singularity of these women's journeys, that is, what they have in common and what is unique to each of them (Figure 1). Because the situation of women living in more than one context of vulnerability to IPV cannot be fully explained if each of these contexts is studied separately from the others, researchers used this approach to deconstruct the assumption 
that women living in a situation of IPV constitute a homogenous group with universal needs and experiences (Oxman-Martinez \& Krane, 2005).

According to Bilge (2009), intersectionality refers to a transdisciplinary theory aimed at understanding the complexity of social identities and inequalities through an integrated approach. It refutes the compartmentalization and prioritization of the major axes of social differentiation that are the categories of sex/gender, class, race, ethnicity, age, disability, and sexual orientation. The intersectional approach goes beyond a simple recognition of the multiplicity of system of oppression operating from these categories and postulates their interaction in the production and reproduction of social inequalities (Brah \& Phoenix, 2004; Collins, 2000; Crenshaw, 1989). Thus, updating the systems of oppression (e.g., sexism, racism, ageism, disability-based discrimination) that social relationships create is at the very core of this approach (Corbeil \& Marchand, 2006). It helps to provide an understanding of how individual, social, and structural factors interact and lead to the marginalization of certain groups of women. As such, it highlights how gender is not the only factor to consider (Anthias, 2005). It emphasizes the productive and reproductive processes of oppression (e.g., racism, ageism, ableism) that categories of identity generate, such as race, class, disability, or sexual orientation, and that make certain groups of women vulnerable to IPV (Brownridge, 2009). Therefore, it enables a deeper understanding of IPV and exposes the multiple, diverse realities of marginalized groups (Davis, 2008).

\section{Method}

This critical literature review is based on the narrative approach (Cronin et al., 2008). The narrative review is a traditional form of literature review. It is a recall of knowledge 
on a specific topic from the relevant literature without an explicit and methodological systematic process of obtaining and analyzing qualitatively the included articles (Audet, 1996; Horvath \& Pewsner, 2004). However, this article integrates methodological elements associated with systematic reviews with the intent to increase the rigor of the process (Cronin et al., 2008; including reading studies twice during their selection and evaluating the reliability of scientific texts). A documentalist from the Institut national de santé publique du Québec developed this documentary research strategy. The following databases were searched: PsychINFO, MEDLINE, SocINDEX, AgeLine, NCJRS, Social Services, Sociological Abstracts, and Erudit. The main key words used (in English and French) were the following: elderly women, immigrant women, women with disabilities, intimate partner violence, scope, consequences, risk and protective factors, explanatory theories, and prevention. Complementary research in the gray literature (e.g., research report) was also conducted, focusing on specialized websites. 1 Additionally, researchers examined bibliographic references of the selected articles. To be selected, an article had to satisfy the following criteria: (1) focus on the issue of IPV experienced by DEI populations, (2) be supported by empirical data obtained through a structured research methodology, (3) be written in French or English, and (4) document a context similar to that of Western country.2 Researchers excluded narrative reviews, expert opinions, descriptive reports of initiatives, theses, dissertations, and book chapters (Table 1). The search turned up 1,466 articles, of which only 56 were kept for having met the selection criteria (Figure 2). Researchers evaluated each article selected for its quality according to a chart that was specially developed for this review (Sasseville, Maurice, Montminy \& Hassan, 2017). This chart contains questions to evaluate the rigor of the research 
methodology and the IPV measure. Two of the authors coded all the selected articles in the NVivo Version 10 analytical software (by QSR International) according to the research questions and emergent themes. These themes are presented in the following section. 
Table 1: Protective and Risk Factors for Intimate Partner Violence: Similarities and Distinctions Between DEI Populations According to Ecological Framework Levels

\begin{tabular}{|c|c|c|}
\hline Environmental & Relational & Individual \\
\hline $\begin{array}{l}\text { Elderly } \\
\text { - Feeling of security regarding } \\
\text { one's environment (PF) } \\
\text { - Living in a rural area } \\
\quad(R F / P F)\end{array}$ & $\begin{array}{l}\text { Elderly } \\
\text { - Age difference between } \\
\text { partners }(R F / P F)\end{array}$ & $\begin{array}{l}\text { Elderly } \\
\text { - Victim's substance use habits (RF) } \\
\text { - Low self-esteem (RF) } \\
\text { - Adoption of risky sexual practices } \\
\text { (RF) } \\
\text { - Victim's antisocial attitude (RF) }\end{array}$ \\
\hline $\begin{array}{l}\text { Having a disability } \\
-\end{array}$ & $\begin{array}{l}\text { Having a disability } \\
-\end{array}$ & $\begin{array}{l}\text { Having a disability } \\
\text { - Being unemployed }(R F)\end{array}$ \\
\hline $\begin{array}{l}\text { Immigrants } \\
\text { - Coming from a non-Western } \\
\text { country (RF) } \\
\text { - Degree of acculturation } \\
\text { (RF) } \\
\text { - Racial discrimination (RF) } \\
\text { - Laws and programs }(R F / P F)\end{array}$ & $\begin{array}{l}\text { Immigrants } \\
\text { - Migration process that } \\
\text { creates conflicts in } \\
\text { couples and changes in } \\
\text { roles (RF) }\end{array}$ & $\begin{array}{l}\text { Immigrants } \\
\text { - Lack of knowledge of the } \\
\text { language (RF) } \\
\text { - Precarious immigration status } \\
\text { (RF) } \\
\text { - Little trust in one's environment } \\
\text { (RF) } \\
\text { - Recent immigration (PF) } \\
\end{array}$ \\
\hline \multicolumn{3}{|c|}{ SIMILAR FACTORS FOUND WITHIN 2 OR 3 GROUPS } \\
\hline $\begin{array}{c}\text { DEI } \\
-\end{array}$ & $\begin{array}{c}\text { DEI } \\
-\end{array}$ & $\begin{array}{l}\text { DEI } \\
\text { - Victimization during childhood } \\
\text { (RF) } \\
\text { - Limitations, disability (RF) } \\
\text { - Spouse's controlling temperament } \\
\text { (RF) } \\
\text { - Physical and psychological health } \\
\text { problems (RF) }\end{array}$ \\
\hline $\begin{array}{l}\text { EI } \\
\text { - Social pressure (RF) } \\
\text { - Social norms and } \\
\text { socialization to traditional } \\
\text { gender roles (RF) } \\
\text { - Isolation and lack of social } \\
\quad \text { support }(R F)\end{array}$ & $\begin{array}{r}\text { EI } \\
-\end{array}$ & $\begin{array}{l}\text { EI } \\
\text { - Religious involvement }(R F) \\
\text { - Violent spouse's alcohol and drug } \\
\text { consumption (RF) } \\
\text { - Victimization during adulthood } \\
\text { (RF) }\end{array}$ \\
\hline DI & $\begin{array}{l}\text { DI } \\
-\end{array}$ & $\begin{array}{l}\text { DI } \\
\text { - Low income (RF) } \\
\text { - Young age (RF) } \\
\text { - Being single, separated or } \\
\quad \text { divorced (RF) }\end{array}$ \\
\hline $\begin{array}{c}\mathbf{D E} \\
-\end{array}$ & $\begin{array}{c}\text { DE } \\
-\end{array}$ & $\begin{array}{l}\text { DE } \\
\text { - Gender (RF) }\end{array}$ \\
\hline
\end{tabular}

Legend: Disability, Elderly and Immigrant (DEI), Elderly and Immigrant (EI) Disability and Immigrant (DI), Disability and Elderly (DE), Risk Factor (RF); Protective Factor (PF); Demonstrated factors (normal type); Factors for which study results are mixed (italic type) 


\section{Results}

\section{What Is the Prevalence of IPV Among the Groups of DEI Women?}

Studies in our review showed that the prevalence of IPV varies from one DEI population to another, both for population- and clinical-based sample data.3 Generally, data from populationbased studies show higher IPV prevalence rates among women with disabilities (Breiding \& Armour, 2015; Cohen \& Maclean, 2004; Mitra \& Mouradian, 2014) and lower among immigrant women (Brennan, 2011; Brownridge \& Hali, 2002; Du Mont \& Forte, 2012; Hyman et al., 2006; Sabina et al., 2015; Sinha, 2013) and elderly women (Brennan, 2012; Centre canadien de la statistique juridique, 2016; Stöckl \& Penhale, 2015).

Particularly, Mitra and Mouradian (2014) found a lifetime prevalence of IPV of $27.9 \%$ for women with disabilities (vs. 17.7\% for nondisabled women). Moreover, Schröttle and Glammeier (2013) found that women with disabilities would be $2-5$ times more likely to experience IPV during their life. Secondary data from Statistics Canada's 2009 General Social Survey (GSS) showed that they would also be nearly twice as likely as nondisabled women (9\% vs. $5 \%$ ) to have experienced IPV in the last 5 years (Sinha, 2013). According to Brieiging and Amour (2015), prevalence of IPV in the last year for women with disabilities varies between $1.7 \%$ and $21 \%$. None of the studies found about women with disabilities were conducted in a clinical sample.

For immigrant women, the data show a lifetime prevalence of $10.8 \%$ versus 23.6\% for nonimmigrant women (Sabina et al., 2015) and an IPV prevalence between $15.5 \%$ (Du Mont \& Forte, 2012) and 17.4\% (Hyman et al., 2006) versus $20.3 \%$ and 
$18.8 \%$ for nonimmigrant women in the last 5 years. In Canada, this rate was $4 \%$ compared with $6.8 \%$ for women in the general population4 (Sinha, 2013). Furthermore, data collected from clinical samples show a lifetime prevalence of IPV of $37.9 \%$ among immigrant women (n 1/4 33) and of 25.2\% among nonimmigrant women (n 1/4 32). AlModallal et al. (2015) found that $78 \%$ of their sample of 300 refugee women had experienced at least one form of IPV, $24.3 \%$ experienced two forms of IPV, and $22.7 \%$ have been victims of three forms of violence in the last year.

Data from population-based studies on elderly women reveal that one in the five elderly couples would have experienced IPV in the past year. This violence affects women in greater proportion than men (20.8\% vs. 6.3\%; Kim \& Sung, 2003). Mezey et al. (2002) found that $21.8 \%$ of women between 53 and 57 years old and $25 \%$ of women between 58 and 69 years old would have been victims of IPV in the last year. However, Brennan (2011) found that Canadians aged older than 55 years were slightly less likely (1\% vs. $2 \%$ ) to report having been a victim of IPV in the 12 months preceding the survey than those aged between 15 and 54 years. Furthermore, data collected from clinical samples showed that lifetime prevalence of elderly women victims of physical, sexual, and psychological violence ranges from $26.5 \%$ to $29.4 \%$ (Bonomi et al., 2007; Montero et al., 2013).

Variations were also found in IPV prevalence rates within each of the DEI groups. For example, women having recently immigrated from a developing country (Brownridge \& Hali, 2002), those with severe disabilities (Schröttle \& Glammeier, 2013) as well as those aged between 50 and 64 years (Stöckl \& Penhale, 2015) were more likely to be affected by IPV than other women of DEI groups. However, only one article among 
those surveyed establishes the prevalence of IPV among women belonging to more than one DEI group. In fact, Frazão, Silva, Norton \& Magalhães (2014) found that $28.6 \%$ of a clinical sample of 70 elderly and disabled women experienced IPV. Finally, the population data seem to underestimate the prevalence rates among the elderly and immigrant women. As a matter of fact, clinical data show that they are victims of IPV as much as nonelderly and nonimmigrant women. These data may be attributable to methodological issues such as a language barrier for immigrant women or a variation in researchers' perceptions about the age at which a person becomes elderly. Violence affects people with disabilities as well as elderly people and immigrants. Populational data need to be interpreted with caution for those populations.

\section{Figure 2. Selection Process of Scientific Articles}

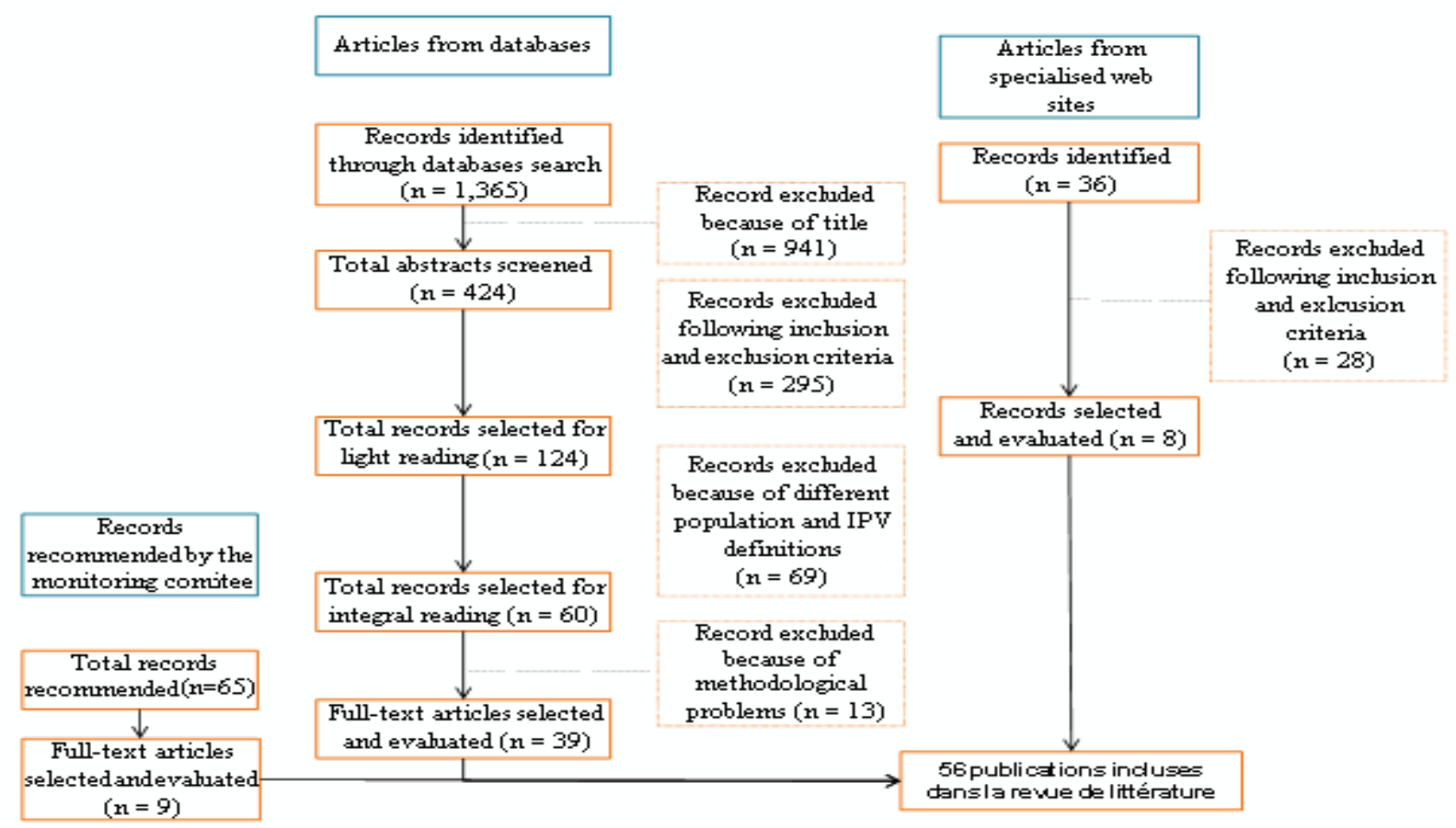




\section{What Are the Forms and Consequences?}

Based on the retained studies, it can be established that DEI women experience the same forms and consequences of IPV as those observed within the general population. For example, they reported being physically, psychologically, sexually, or economically abused (Bonomi et al., 2007; Mezey et al., 2002; Mitra \& Mouradian, 2014; Montero et al., 2013; Schröttle \& Glammeier, 2013). Although often trivialized, verbal abuse is also recognized in the scientific literature. It usually accompanies other forms of violence and allows the abusive partner to control his victim (Gouvernement du Québec, 1995; Heise \& Garcia-Moreno, 2002). It has negative physical and Figure 2. Selection process of scientific articles. psychological consequences for the victims (Howe $\&$ Alpert, 2009). The specific ways in which these forms of violence are manifested characterize the experience of IPV by DEI groups, including abuse, neglect, and control over sexual health (e.g., a violent spouse's refusal to use a condom) of elderly women and those with disabilities (Finfgeld-Connett, 2014; Gravel et al., 1997), as well as forms of violence related to the migration process (e.g., threat of deportation) among immigrant women (Raj et al., 2005). In terms of consequences, some studies identified an accrued vulnerability among elderly women with disabilities, which may result from the cumulative consequences of IPV over their lifetime and may tend to become chronic over time (Finfgeld-Connett, 2014; Montero et al., 2013). Moreover, some studies established that DEI women's disability is often the result of the IPV that they have experienced (Divin et al., 2013; Finfgeld-Connett, 2014). 


\section{What Are the Similarities and Distinctions Concerning the Risk Factors for IPV}

\section{Among DEI Women?}

Etiological studies documenting protective and risk factors for IPV among DEI women focused on individual characteristics and generally on the same variables as those used for the general population (Brownridge, 2009). It is largely the qualitative studies that provided a better understanding of how their respective contexts modulate these factors because they took a more global approach to the various ecological levels (individual, relational, and environmental). Table 1 offers a synthesis of these factors according to the ecological framework. The listed risk factors come from the studies identified as the most reliable. Thus, it is not because a risk factor is not addressed in this review that it is not part of the reality of DEI women.

Certain factors associated with IPV were explained in the literature as being distinct due to their association with a context of vulnerability. This was particularly the case for studies conducted on immigrant women that established an association between an increased risk of experiencing IPV and being from a non-Western country (Hyman et al., 2006), the duration of an immigrant's stay in the new host country (Hyman et al., 2006), and a precarious immigration status such as sponsorship (Raj et al., 2005).

Furthermore, a lack of knowledge of the language and changes in a couple's socioeconomic status were also identified as drivers of conflict and stress (Guruge et al., 2010; Rees \& Pease, 2007). Together, these factors were explained as being specific to the migration process and as contributing to the occurrence or presence of IPV.

Moreover, the consumption of alcohol and medication (Halicka et al., 2015; Stöckl et al., 2012; Teaster et al., 2006), a low self-esteem (Finfgeld-Connett, 2014), the 
adoption of risky sexual practices (Sormanti et al., 2004), and a large age difference between partners and living in a rural area (Yon et al., 2014) are factors that are generally found to be associated with IPV in older women. Nonetheless, the influence of the context of vulnerability on these factors remains unknown, as they remain altogether generic. The same is true for the factors that explain IPV in women with disabilities, where a more obvious tendency is observed for studies to document the same factors as those used for the general population.

An intersectional analysis enabled us to identify a certain number of risk factors associated with an increased risk of experiencing IPV and whose contexts play a role in the victimization experienced by DEI women (Table 1). These risk factors can be grouped into four broad categories: (1) exposure to dynamics of violence over the course of one's life that the context of vulnerability often creates, for example, abuse during childhood, victimization during adulthood due to care received for a disability, and exposure to war (Guruge et al., 2010; Stöckl et al., 2012); (2) increased dependence on the spouse due to obstacles that the woman's situation creates, for example, social isolation due to illness, a disability, linguistic barriers, or the loss of a family support network (Finfgeld-Connett, 2014; Guruge et al., 2010); (3) a violent spouse's controlling and jealous temperament that is sanctioned by cultural norms conducive to tolerance for violence or supportive of patriarchy, for example, traditional gender socialization process and socialization of women with disabilities to be tolerant and complacent (Lee, 2007; Teaster et al., 2006); and (4) cumulative contexts of vulnerability, such as being an elderly woman with a disability or an immigrant woman with a disability (Hyman et al., 2006; Yon et al., 2014). 
Which Explanatory Theories Have Been Proposed to Comprehend the Violence That DEI Women Experience?

There are multiple theories that attempt to explain the IPV that DEI women experience (Figure 3). These theories are generally the same as the ones used to account for IPV within the general population: those with a psychological, sociological, ecological, or feminist theme. Although most of the articles surveyed use the feminist approach, some of them use more than one approach. According to researchers, this allows a more indepth analysis of the problematic of DEI women experiencing IPV. However, the different theories are discussed separately in the text to facilitate the readers' understanding. Yet, none of the theories proposed to date can fully explain why DEI women are more vulnerable to IPV; likewise, no empirical proof exists to support these theories.

According to psychological theories, IPV may be attributed to the individual characteristics of the people involved. In the studies reviewed that fall into this category, a link was established between alcohol and medication consumption and IPV perpetrated or experienced by the elderly (Kim \& Sung, 2003; Stöckl et al., 2012). The authors explained that substance use may result in lower inhibitions at the source of conflicts leading to violence in couples. The presence of certain mental health problems may also account for the IPV experienced. For example, Lazenbatt, Devaney \& Gildea (2013) explained that experiencing violence during different periods of one's life (e.g., during childhood and when in a couple) has negative impacts on older women's mental health, leading to severe depression and anxiety problems. These mental health problems may 
constitute in themselves a risk factor for the victimization of older women by affecting their capacity to seek help and break the cycle of violence (Lazenbatt et al., 2013).

For their part, sociological theories explain the problem of violence as being learned or reactive. Like in the literature regarding women in general, the experience of childhood victimization is a widely proposed factor due to its positive association with violence victimization or perpetration during adulthood (Finfgeld-Connett, 2014; Hyman et al., 2006; Schröttle \& Glammeier, 2013; Stöckl \& Penhale, 2015). In this respect, some studies highlighted that the particular context of DEI women exposes them to a process of traditional gender role socialization by putting them in a position of vulnerability to violence because they have not developed the capacities and skills necessary to recognize and react appropriately to this violence (Al-Modallal et al., 2015; Finfgeld-Connett, 2014; Hyman et al., 2006; Schröttle \& Glammeier, 2013; Stöckl \& Penhale, 2015). For example, this is the case in studies showing that IPV affects a larger proportion of immigrant women from developing countries than of those from developed countries. This situation may be attributed to these women's stronger adherence to patriarchal values, where violence may be socially accepted as a punitive measure in the country of origin (Hyman et al., 2006; Lee, 2007). The same observation holds true for elderly women and women with disabilities. In an exploratory study where the aim was to understand the problem of older women experiencing IPV, Montminy and Drouin (2009) explained that the influence of Judeo-Christian values leads these women to remain in situations of violence, as leaving their spouse would represent a source of shame and guilt due to the importance they may attribute to family preservation (Montminy \& Drouin, 2009). Supporting themselves with the work of Chenoweth (1996), Schröttle and 
Glammeier (2013) explained the greater vulnerability of women with disabilities to IPV as being due to the victimization they experienced during childhood as well as a genderbased socialization process (e.g., socialized to conform, considered to be "eternal children," overprotected due to their disability), which inhibit the acquisition of capacities allowing them to establish appropriate boundaries around violence.

Social factors (e.g., unemployment, poverty), together with living conditions (e.g., immigration process, aging process), were found to generate stress in couples as well as to trigger or aggravate IPV (Lowenstein \& Ron, 1999; Zannettino, 2012). This is the case for the immigration process that represents a stressful life transition, bringing about changes (e.g., role changes, exposure to new values, weakening of economic conditions) and disturbances in couples that may lead to an increase in conflicts (Zannettino, 2012). The aging process is another transition that may generate stress in couples through the role changes that it entails, including children leaving the family home or retirement, or the exhaustion of one of the spouses from assuming caregiver responsibilities due to, for example, illness, functional limitations, or cognitive impairments (Lowenstein \& Ron, 1999; Montminy, 2005).

Ecological theories consider IPV to be a manifestation of a multifactorial phenomenon. Studies based on these theories tended to demonstrate that IPV against DEI women is the consequence of an interaction between (1) individual factors: age, gender, health status, alcohol and drug consumption, disability, and victimization during childhood (Divin et al., 2013; Du Mont \& Forte, 2012; Finfgeld-Connett, 2014; Schröttle \& Glammeier, 2013; Smith, 2008; Teaster et al., 2006; Zannettino, 2012); (2) socioeconomic factors: poor education, low income, and poverty (Divin et al., 2013; Finfgeld-Connett, 2014; 
Vives-Cases et al., 2010, 2013); (3) family factors: little support from family members (Guedes et al., 2015; VivesCases et al., 2010; Zannettino, 2012); (4) community factors: difficulties accessing services, living in a rural area (Finfgeld-Connett, 2014; Schröttle \& Glammeier, 2013; Teaster et al., Psychological (Substance use and health problem) None (Sociological (cultural acceptance) Feminist (patriarchy and laws) With Disabilities Sociological (learning traditional norms, importance, family, religion) Ecological (interactions between individual, familial, cultural and social factors) Feminism (patriarchy) Ecological (cumulative effects of risk factors over the course of a lifetime) Feminism (intersectional between gender, ethnicity, disability and social class) Sociological (caregiver's stress and stress linked to the immigration and ageing processes) Immigrant Elderly Figure 3. Explanatory theories for intimate partner violence experienced by disabilities, elderly women, and immigrant women with disabilities. 2006; Zannettino, 2012); and (5) sociocultural factors: social and patriarchal norms, stigmatization, and discrimination (Divin et al., 2013; Du Mont \& Forte, 2012; Guedes et al., 2015; Hyman et al., 2011; Zannettino, 2012). Together, these factors act cumulatively over a lifetime, making DEI women more vulnerable (Divin et al., 2013; FinfgeldConnett, 2014; Stöckl \& Penhale, 2015; Teaster et al., 2006).

Finally, studies based on feminist theories explain IPV against DEI women within a context of domination of men over women and the patriarchal social structures that perpetuate it. Abusive spouses' personality traits - their adherence to patriarchal values of domination and controlling behaviors expressed as possessiveness and jealousy-are all elements that explain the perpetration of IPV against DEI women (Brownridge, 2006; Du Mont \& Forte, 2012; Nosek et al., 2001; Yon et al., 2014). Results of the selected 
studies also highlighted how social structures institutionalize patriarchy, which can create or legitimize dominant-dominated relationships (Kyriakakis et al., 2012). This was the case in the study by Morash et al. (2007) who explained how immigration policies (e.g., sponsorship) can make immigrant women who are experiencing IPV more vulnerable, with men using the threat of expulsion to discourage the exposure of the violence.

Figure 3. Explanatory Theories for Intimate Partner Violence Experienced by

\section{DEI Women}

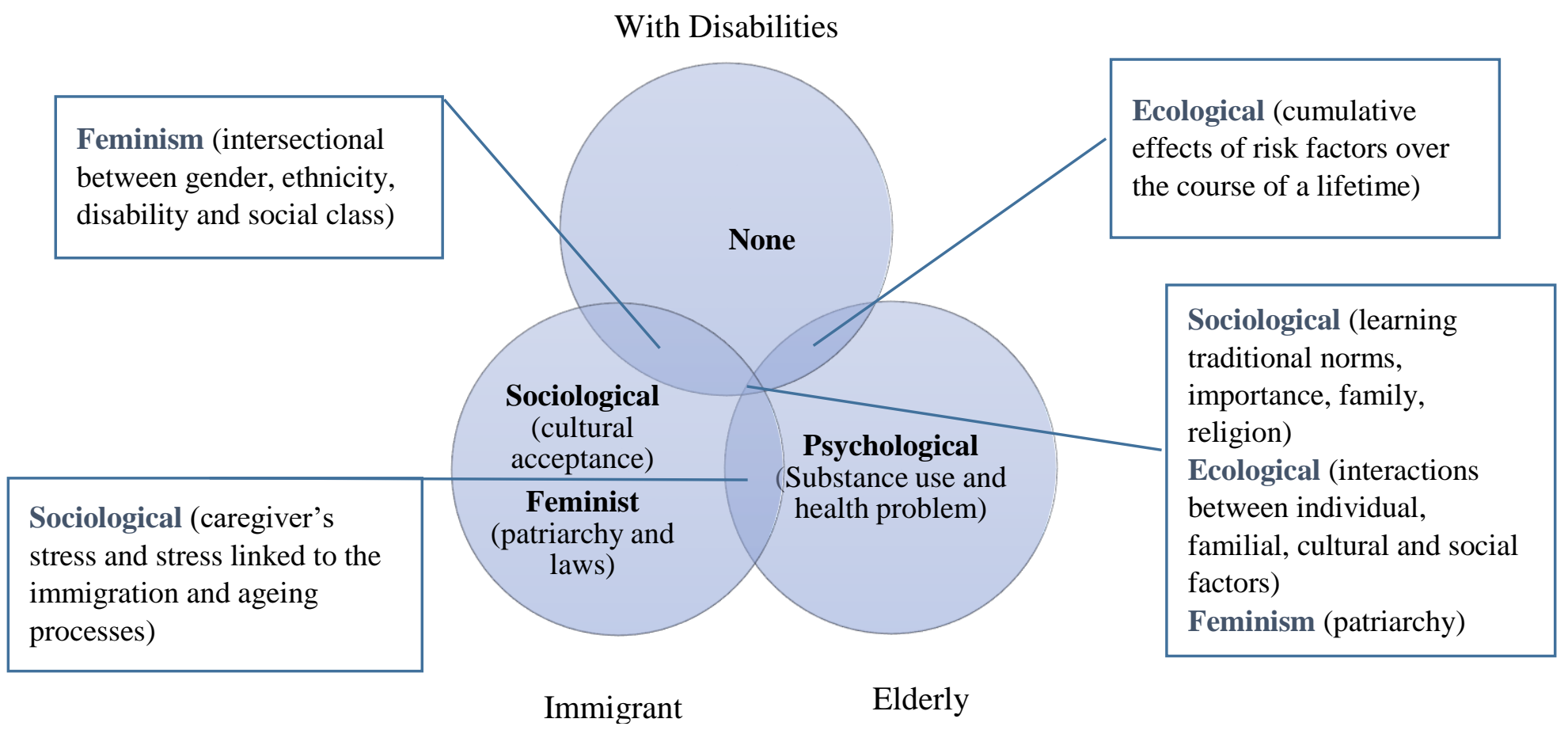




\section{How Can IPV Be Prevented in the DEI Population?}

Studies on the efficiency of prevention initiatives for DEI women are almost nonexistent. Among the corpus of articles that were identified, the only ones assessing the efficiency of early detection initiatives for IPV were those by Messing et al. (2013) and Hassan et al. (2011). In the other studies (mainly those documenting risk factors), the results were used to identify their implications for the prevention of IPV against DEI women. In the context of primary prevention of IPV against DEI populations, three themes were identified as follows: early detection, actions regarding health determinants, and conditions needed to successfully support prevention activities.

In the scientific literature, the efficiency of early detection of IPV is the subject of much debate (Hassan et al., 2011; McGarry et al., 2011). Hassan et al. (2011) conducted a systematic literature review to help identify the most appropriate tools for early detection among immigrant and refugee women but found insufficient evidence to recommend regular use of such tools considering the potential negative impacts (e.g., loss of status). Rather, the proper solutions demand an awareness of the potential signs of IPV and an evaluation when there is reasonable suspicion that it is occurring (Hassan et al., 2011). These results reflect the work conducted regarding elderly women and women with disabilities (Breiding \& Armour, 2015; Lazenbatt et al., 2013; McFarlane, Hughes, Nosek, Groff, Swedlend \& Mullen, 2001; McGarry et al., 2011; Mitra \& Mouradian, 2014; Montminy, 2011; Sormanti et al., 2004; Sormanti \& Shibusawa, 2008).

Furthermore, several studies have revealed the importance of adapting the screening tools to account for issues that are specific to DEI women. The work by Messing et al. (2013) on this subject showed that the adapted version of the Danger Assessment for immigrant 
women predicts the risk of IPV victimization more precisely than the original tool, as it takes into account risk factors that are specific to the context of immigration. Stöckl and Penhale (2015) suggested that screening for IPV in older women should include questions about the spouse's controlling behavior because this form of violence is more likely to occur in these couples and to be considered "acceptable." A similar opinion regarding women with disabilities highlights the importance of questioning forms of disability-related violence, such as limiting access to medicines or other comforts (McFarlane et al., 2001). Further research is nonetheless necessary to demonstrate the efficiency of such recommendations, particularly for elderly women and women with disabilities.

For their part, etiological studies identified a certain number of strategies targeting health determinants that could improve IPV prevention among DEI women. Some of these strategies are more general, such as the implementation of awareness programs promoting a shift in social norms toward more egalitarian relations between men and women. Others are more specific to DEI women, their families, and their communities. The recommendations made include as: (1) building awareness of issues likely to generate or exacerbate violence in a couple and of specific manifestations of the various forms of violence (Ahn, 2006; Du Mont et al., 2012; Hyman et al., 2006; Lee, 2007; Schröttle \& Glammeier, 2013; Teaster et al., 2006; Yon et al., 2014); (2) implementation of initiatives that enable the social integration of DEI women, including social programs (e.g., housing, daycare, transportation) and employment (Hyman et al., 2011); (3) education on laws and available programs (Guruge et al., 2010; Hyman et al., 2011); (4) reinforcement of social support networks to reduce stress associated with particular life 
contexts (e.g., providing respite for elderly spouses); and (5) strengthening of community ties (Guruge et al., 2010; Hyman et al., 2011; Yon et al., 2014).

These actions should depend on three conditions to ensure their success: (1) interdisciplinary training of the various intersectoral partners, for example, in health and justice (Mitra \& Mouradian, 2014; Yon et al., 2014) with special attention paid to social stereotypes and prejudices (McGarry et al., 2011); (2) intersectoral collaboration to share and improve partnerships between different services meant for these clients (Hyman et al., 2011; Lazenbatt et al., 2013; Mitra \& Mouradian, 2014; Yon et al., 2014); and (3) adoption of a communitybased participatory approach that involves DEI women experiencing IPV, as well as the community leaders who represent them, to determine appropriate actions based on their realities and needs (Du Mont et al., 2012; Schröttle \& Glammeier, 2013; Teaster et al., 2006).

\section{Discussion}

The analysis of the results from the reviewed studies led to three broad conclusions that provide a better understanding of the specific reality and of the intersections of the groups that experience Sasseville et al. 7 IPV. These findings highlight the importance of studying violence in its sociocultural context, for gender alone is not sufficient to account for the multiple identity-related dimensions of a person and their experience with IPV (Blais, 2016).

\section{DEI Women Suffer From Violence Forms That Depend of the Context of Vulnerability}

The first finding is that belonging to one of the DEI groups exposes these women to adverse conditions that accumulate over the course of their lives, making it difficult for 
them to get help and, consequently, to end the cycle of violence. Some authors will refer to disadvantages (regarding health, socioeconomic conditions, etc.) that isolate these women in a form of crystallization of the violence experienced over the course of their lives (McGarry et al., 2011). Discrimination and stigmatization stemming from having a “minority" status, among other things, characterize these adverse effects (Blais, 2016). It thus appears that DEI women's vulnerability to IPV is not a consequence of their individual characteristics (Sasseville, Maurice, Montminy \& Hassan, 2017). Rather, it seems to be the result of being in one of these contexts of vulnerability that affect the experience of violence. Although DEI women experience the same forms of violence as the general population, the violence they experience manifests itself in particular ways (abuse, control over sexual life, control of migration status, etc.) as well as the risk factors (e.g., interpersonal and environmental). The particular contexts of vulnerability in which DEI women live also lead to more severe consequences (e.g., diseases that become chronic) of a lifetime of experiencing IPV (Sasseville, Maurice, Montminy \& Hassan, 2017).

\section{Women With IPV Have a Higher Risk of Experiencing IPV Than Women in General \\ Population}

As such, this analysis highlights the factors that impact DEI women's experience of IPV victimization that differ from those in the general population. First, lifetime exposure to multiple victimizations in intimate relationships is associated with a higher risk of experiencing IPV (Du Mont et al., 2012; Lee, 2007; Stöckl et al., 2012). The precarious socioeconomic conditions such as a lack of access to employment and stress related life changes such as the presence of age-related illness and migration processes are also 
among these factors. While the first is associated with an increase of women's dependence on their violent spouse by decreasing their access to privileges enjoyed by other women (Guedes et al., 2015; Morash et al., 2007), the second is associated to the occurrence or aggravation of violence in a couple (Lowenstein \& Ron, 1999; Zannettino, 2012). Finally, it appears that processes of discrimination and exclusion stemming from a lack of conformity to social stereotypes due to personal differences related to disability, age, or ethnicity (Hyman et al., 2006; Sormanti et al., 2004; Yon et al., 2014) and specific cultural factors associated with belonging to the DEI groups, namely, social norms favorable to violence instilled through the socialization process, religiosity, or other indirect elements like coming from a non-Western country are also impacting DEI women's experience of IPV victimization (Hyman et al., 2006; Lee, 2007; Montminy \& Drouin, 2009).

\section{IPV Affects Certain Subgroups of DEI Women in Greater Proportion}

A second finding is that IPV does not affect women belonging to a same group in a uniform manner. Within these groups, IPV impacts some subgroups in greater proportions. Indeed, studies conducted with immigrant women that, based on a hierarchization in the categorization of status (e.g., coming from a nonWestern country or not), showed that IPV affects in greater proportion women from non-Western countries and whose immigration is recent (Brownridge \& Hali, 2002). The same was found for 50to 64-year-old women with a higher prevalence of IPV than those over 64 years old due to psychosocial factors generating stress (e.g., children leaving home and retirement) and violence in the couple (Mezey et al., 2002; Stöckl \& Penhale, 2015). Similarly, among women with disabilities, certain profiles were found to be more at risk of suffering IPV, 
for example, women with severe disabilities (visual, auditory, mental) compared with women with less severe disabilities (Schröttle \& Glammeier, 2013).

These results are consistent with an intersectional reading that does not consider violence against women homogeneously but focuses rather on the heterogeneity of women's social statuses and experiences, as well as on the plurality of resulting identity-related components (Corbeil \& Marchand, 2006). These results therefore call for caution because a homogenous and universal reading of the violence experienced by these groups of women could hide the existence of differences within each one of them. As advanced by Corbeil and Marchand (2006), examining them as a "whole" would amount to adopting a colonialist approach, which risks confining them to a homogenizing status with no other experience being possible. However, variation within each of these subgroups remains largely undocumented. It is still impossible to say whether the differences observed are statistically significant (Sasseville, Maurice, Montminy \& Hassan, 2017) and whether they are the result of an accumulation of disadvantages determined by the accumulation of minority statuses (in other words, having a minority status within a minority group). Further studies are therefore necessary to better understand the factors that are involved in the "intersections" and that can increase the vulnerability to IPV of DEI women within these subgroups as well as those who increase their resilience.

\section{Belonging to More Than One DEI Group Exposes Women to Cumulative Effects of IPV}

Finally, it is reasonable to believe that belonging to more than one vulnerable group (intersections) exposes DEI women to the cumulative effects of IPV and creates disadvantages, discriminations, and multiple oppressions. This finding is based on the 
two preceding ones that clearly demonstrate the often adverse effects observed within a minority group. However, few studies have been conducted on the issue of cumulative contexts of vulnerability. The two studies reviewed (elderly women with disabilities and elderly immigrant women) did not systematically study the cumulative effects of these statuses. Their results, however, present interesting elements for an intersectional approach.

According to the study by Hyman et al. (2006), disability is significantly associated with a higher risk of experiencing IPV in groups of elderly and immigrant women living in precarious socioeconomic conditions (e.g., poverty). Lee (2007) showed that this tendency leads to discrimination (racial- and disability based) as a result of having a minority status and to the presence of barriers (e.g., linguistic, access to services, laws, and programs), making it difficult to access support. For their part, Divin et al. (2013) studied IPV in 55- to 75-year-old Mexican American women with a mobility impairment and helped clarify how the contexts of a person's life influence social and cultural factors. Their results showed that these women had gone through multiple victimizations influenced by elements of Mexican culture (e.g., socialization process based on patriarchy and religion). Such multiple victimizations lead to social marginalization that creates a lack of support (e.g., family) and an inability to integrate into the labor market due to the spouse's controlling behavior. When these women are older, the cumulative health-related consequences of experienced victimizations (disability and chronic diseases) combined with religious beliefs (e.g., the importance of family preservation) as well as poverty (difficulty integrating into the labor market, due to not having developed the necessary skills) exacerbate these women's vulnerability to IPV. 
The available data, however, provide an incomplete picture that precludes an understanding of the reality of DEI women's experiences with IPV and contributes to the invisibility of their reality (Brownridge, 2006; Montminy \& Drouin, 2009; Shah et al., 2016). This lack of understanding is even more obvious when it comes to the issue of cumulative contexts of vulnerability (Sasseville, Maurice, Montminy \& Hassan, 2017). There are inherent limitations in the available research. The current trend in studies is to examine IPV against DEI women with the same indicators as those used in the general population, without necessarily documenting those that are specific to these contexts of vulnerability (intersections; Brownridge, 2009). Moreover, different methodological issues and numerous variations in study design (e.g., the way the study population is defined, the forms of IPV studied, the sample composition) make it difficult to compare the data and to precisely establish the scope, forms, and consequences of the IPV experienced by DEI women (Bonomi et al., 2007; Sasseville, Maurice, Montminy \& Hassan, 2017; Sinha, 2012).

\section{Preventive Actions Should Be Aimed Particularly at Reducing Risk Factors Specific to the Contexts of Vulnerability}

Finally, the available data provide an incomplete picture of the various levels of factors that can influence the vulnerability of DEI women, for it is generally women's individual and sociodemographic characteristics that constitute the studied variables (Brownridge, 2009; Sasseville, Maurice, Montminy \& Hassan, 2017). As previously mentioned, there is no empirical evidence supporting the elements explaining IPV against DEI women. Thus, further studies are needed to better develop knowledge on the accumulation of contexts of vulnerability, a reality that is almost excluded in the studies. Moreover, the 
theories put forth to date fail to fully explain why these women are more vulnerable to IPV than those in the general population. Consequently, the state of knowledge is underdeveloped in terms of initiatives that could prevent violence against these women. In this regard, it is important to make full use of existing data to perform cross-sectional analyses on the contexts of vulnerability to IPV.

\section{Implications for Research, Practice, and Policy}

The main conclusions of this literature review have multiple implications for research and interventions focused on DEI women. They highlight the necessity of addressing the notion of contexts of vulnerability from a much wider perspective, given that belonging to one or more of these contexts causes DEI women to face disadvantages and multiple oppressions (Blais, 2016). This conclusion is particularly important for the design of programs and services for DEI women. The violence that these women experience is especially complex and requires a response modulated to the singularity of their experiences (Brownridge, 2009). Currently, the programs and services for DEI women are often developed from a clientelist perspective (e.g., programs for elderly women, immigrant women, or women with disabilities) thus creating a fragmented response to their needs without considering women in their entirety (Sasseville, Maurice, Montminy \& Hassan, 2017). Hence, the policies, programs, and interventions that are created for them must take into account the social determinants associated with IPV and facilitate links between the issues experienced by these groups of women. Administrators and ministerial representatives have to elaborate specific programs and policies using the social determinants of health tailored to the DEI populations. Social workers should also be trained in this subject in order to make informed interventions. 
Regarding research, there is an urgent need to conduct additional work with DEI women experiencing IPV to better understand their reality and the risk factors for victimization and perpetration that are common and specific to each of these clienteles. There is also a pressing need to better document and evaluate current interventions to identify the best prevention and intervention strategies. Finally, it is important to remember that large national surveys (e.g., the GSS data) already provide data relative to these populations. Researchers now need to examine the intersections of these data to better grasp or understand the reality of women living in more than one of these contexts of vulnerability to IPV.

\section{Conclusion}

Based on an intersectional approach, this critical literature review brought out similarities and distinctions pertaining to the scope, forms, consequences, risk factors, explanatory theories, and prevention strategies for DEI women experiencing IPV. The relevance of such an interest is based on the fact that since the 1970s, the scientific literature has been particularly focused on the issue of IPV that young Western women in a heterosexual relationship experience (Brownridge, 2009), therefore silencing the reality of DEI women, especially those living with more than one of these contexts. The results of this review demonstrate that DEI women's vulnerability to IPV manifests itself in various ways, including the higher proportions in which IPV affects DEI women, as well as the forms of violence and risk factors specifically associated with these contexts of vulnerability. DEI women are exposed to disadvantages and multiple sources of oppression stemming from the fact that they belong to a group with "minority status," which makes it difficult for them to break the cycle of violence. Furthermore, those living 
with an accumulation of these contexts are faced with additional obstacles that remain largely unknown. For practice environments confronted with these women's complex experiences cumulating several of these contexts, more refined knowledge is needed. Hence, it seems essential that research and practice environments cooperate to better understand the intersections related to these contexts of vulnerability to develop interventions adapted to these clients' specific needs.

\section{Critical Findings}

- Vulnerability to IPV manifests itself among groups of DEI women in various ways, such as through increased risks of experiencing IPV, through forms of violence particular to the context of vulnerability but also through exposure to a variety of barriers that complicate the women's capacity to escape the cycle of violence.

- IPV affects certain subgroups of DEI women in greater proportions, including women from developing countries and whose immigration is recent, who have severe disabilities, and who are from 50 to 64 years old.

- Although DEI women share factors that are universal to all forms of violence (e.g., maltreatment during childhood) with women from the general population, risk factors resulting from the context in which they live distinguish their experience with IPV.

- Preventive actions should be aimed particularly at reducing risk factors specific to the contexts of vulnerability. 


\section{Main Conclusions Regarding Research, Practice, and Policy}

- Further studies are needed to better develop knowledge on the accumulation of contexts of vulnerability, a reality that is almost excluded in the studies.

- It is important to make full use of existing data to perform cross-sectional analyses on the contexts of vulnerability to IPV.

- Administrators and ministerial representatives have to elaborate specific programs and policies using the social determinants of health tailored to the DEI populations. Social workers should also be trained in this subject in order to make informed interventions.

\section{Acknowledgments}

We want to extend our gratitude to Julie Laforest and Geneviève Lessage, from Institut national de santé publique du Québec, who provided supports and comments on this project research.

\section{Declaration of Conflicting Interests}

The author(s) declared no potential conflicts of interest with respect to the research, authorship, and/or publication of this article.

\section{Funding}

The author(s) disclosed receipt of the following financial support for the research, authorship, and/or publication of this article: The authors received financial support for the research and authorship from Fonds québécois de recherche sur la Société et la culture. ORCID iD Nathalie Sasseville https://orcid.org/0000-0002-5226-3123 


\section{Notes}

1. These sites included SantéCom, Centre de recherche interdisciplinaire sur la violence

familiale et faite aux femmes, Statistique Canada, and Institut de la statistique du Québec.

2. The list of Organization for Economic Cooperation and Development member countries was used were available at http://www.oecd.org/about/membersandpartners/list-oecd-member-countries.htm.

3. Clinical samples are made of women whose intimate partner violence situation is recognized and supported. These include women living in shelters.

4. The expression "general population" refers to young Caucasian women without disabilities. 


\section{References}

Ahn, B. (2006). Correlates of physical violence in marital relationships among first-generation Korean Americans. International Social Work, 49(2), 208-217.

Al-Modallal, H., Abu Zayed, I., Abujilban, S., Shehab, T., \& Atoum, M. (2015). Prevalence of intimate partner violence among women visiting health care centers in Palestine refugee camps in Jordan. Health Care for Women International, 36(2), 137-148.

Anthias, F. (2005). Social stratification and social inequality: Models of intersectionality and identity. In F. Devine, M. Savage, J. Scott, \& R. Crompton (Eds.), Rethinking class: Culture, identities and lifestyles (pp. 24-45). Palgrave Macmillan.

Audet, N. (1996). Critical reading of summary articles. In A. Simpson, C. Beaucage, \& B. Viger (Eds.), Applied epidemiology: An introduction to critical reading of health science literature (3rd ed., pp. 414-445). Gaétan Morin.

Bilge, S. (2009). Feminist theories of intersectionality. Diogenes, 225(1), 70-88. https://doi.org/10.3917/dio.225.0070

Blais, M. (2016). Rendre compte des appartenances multiples: intersection des appartenances ethnoculturelles et d'orientation sexuelle. In S. Brotman, et al. (Eds.), Intersections: Cultures, sexualites et genres (pp. 20-51). Presses de 1’Université du Québec.

Bonomi, A. E., Anderson, M. L., Reid, R. J., Carrell, D., Fishman, P. A., Rivara, F. P., \& Thompson, R. S. (2007). Intimate partner violence in older women. The Gerontologist, 47(1), 34-41.

Brah, A., \& Phoenix, A. (2004). Ain't I a woman? Revisiting intersectionality. Journal of International Women's Studies, 5(3), 75-86.

Breiding, M. J., \& Armour, B. S. (2015). The association between disability and intimate partner violence in the United States. Annals of Epidemiology, 25(6), 455-457.

Brennan, S. (2011). Self-reported spousal violence, 2009: Family violence in Canada: a statistical profile. Statistics Canada.

Brennan, S. (2012). Victimization among older Canadians, 2009. Statistics Canada. Brownridge, D. A. (2006). Partner violence against women with disabilities: Prevalence, risk, and explanations. Violence Against Women, 12(9), 805-822.

Brownridge, D. A. (2009). Violence against women: Vulnerable populations. Routledge.

Brownridge, D. A., \& Hali, S. (2002). Double jeopardy? Violence against immigrant women in Canada. Violence and Victims, 17(4), 455-471.

Canadian Center for Justice Statistics. (2016). Family violence in Canada: A statistical profile, 2014. Statistics Canada. 
Chenoweth, L. (1996). Violence and women with disabilities: Silence and paradox. Violence Against Women, 2(4), 391-411.

Cohen, M. M., \& Maclean, H. (2004). Violence against Canadian women. BMC Women's Health, 4(1), 1-24.

Collins, P. H. (2000). Black feminist thought: Knowledge, Consciousness, and the politics of empowerment [1990]. Routledge.

Corbeil, C., \& Merchand, I. (2006). Think of feminist intervention in terms of an intersectional approach. New Social Practices, 19(1), 40-50.

Crenshaw, K. (1989). Demarginalizing the intersection of race and sex: A Black feminist critique of discrimination doctrine, feminist theory and antiracist practice. The University of Chicago Legal Forum, 89, 139-167

Cronin, P., Ryan, F., \& Coughlan, M. (2008). Undertaking a literature review: A step-by-step approach. British Journal of Nursing, 17(1), 38-43.

Davis, K. (2008). Intersectionality as buzzword: A sociology of science perspective on what makes a feminist theory successful. Feminist Theory, 9(1), 67-85.

Divin, C., Volker, D. L., \& Harrison, T. (2013). Intimate partner violence in Mexican-American women with disabilities: A secondary data analysis of cross-language research. Advances in Nursing Science, 36(3), 243-257.

Du Mont, J., \& Forte, T. (2012). An exploratory study on the consequences and contextual factors of intimate partner violence among immigrant and Canadian-born women. BMJ Open, 2(6), 1-9.

Du Mont, J., Hyman, I., O’Brien, K., White, M. E., Odette, F., \& Tyyskä, V. (2012). Factors associated with intimate partner violence by a former partner by immigration status and length of residence in Canada. Annals of Epidemiology, 22(11), 772-777.

Finfgeld-Connett, D. (2014). Intimate partner abuse among older women: Qualitative systematic review. Clinical Nursing Research, 23(6), 664-683.

Frazão, S. L., Silva, M. S., Norton, P., \& Magalhães, T. (2014). Domestic violence against elderly with disability. Journal of Forensic and Legal Medicine, 28, 19-24.

Government of Quebec. (1995). Spousal violence intervention policy. Prevent, detect, counter. https://publications.msss.gouv.qc.ca/ msss/fichiers/2000/00-807/95-842.pdf

Gravel, S., Beaulieu, M., \& Lithwick, M. (1997). When aging together hurts: Abuse between older spouses. Criminology, 30(2), 67-85.

Guedes, D. T., Alvarado, B. E., Phillips, S. P., Curcio, C. L., Zunzunegui, M. V., \& Guerra, R. O. (2015). Socioeconomic status, social relations and domestic violence (DV) against elderly people in Canada, Albania, Colombia and Brazil. Archives of Gerontology and Geriatrics, 60(3), 492-500. 
Guruge, S., Khanlou, N., \& Gastaldo, D. (2010). Intimate male partner violence in the migration process: Intersections of gender, race and class. Journal of Advanced Nursing, 66(1), 103-113.

Halicka, M., Halicki, J., Kramkowska, E, \& Szafranek, A. (2015). Law enforcement, the judiciary and intimate partner violence against the elderly in court files. Studia Socjologiczne, 2(217), 195-214.

Harper, E., \& Kurtzman, L. (2014). Intersectionality: Theoretical perspectives and uses in feminist research and intervention. New Social Practices, 26(2), 15-27.

Hassan, G., Thombs, B., Rousseau, C., Kirmayer, L., Feightner, J., Ueffing, E., \& Pottie, K. (2011). Intimate partner violence: Evidence review for newly arriving immigrants and refugees. In K. Pottie, C. Greenaway, J. Feightner, V. Welch, H. Swinkels, M. Rashid, L. Narasiah, L. J. Kirmayer, E. Ueffing, N. E. MacDonald, G. Hassan, M. McNally, K. Khan, R. Buhrmann, S. Dunn, A. Dominic, A. E. McCarthy, A. J. Gagnon, C. Rousseau, ... P. Tugwel (Eds.), Evidence-based clinical guidelines for immigrants and refugees (appendix 13, pp. 1-13). Canadian Medical Association.

Heise, L., \& Garcia-Moreno, C. (2002). Violence by intimate partners. In E. G. Krug, L. L. Dahlberg, J. A. Mercy, A. Zwi, \& R. LozanoAscencio (Eds.), World Report on Violence and Health (pp. 97-135). World Health Organization.

Horvath, A. R., \& Pewsner, D. (2004). Systematic reviews in laboratory medicine: Principles, processes and practical considerations. Clinica Chimica Acta, 342(1-2), 23-39.

Howe, M. E., \& Alpert, E. J. (2009). A public health approach to intimate partner violence. In C. Mitchell \& D. Anglin (Eds.), Intimate partner violence: A health-based perspective (pp. 275-287). Oxford University Press.

Hyman, I., Forte, T., Mont, J. D., Romans, S., \& Cohen, M. M. (2006). The association between length of stay in Canada and intimate partner violence among immigrant women. American Journal of Public Health, 96(4), 654-659.

Hyman, I., Mason, R., Guruge, S., Berman, H., Kanagaratnam, P., \& Manuel, L. (2011). Perceptions of factors contributing to intimate partner violence among Sri Lankan Tamil immigrant women in Canada. Health Care for Women International, 32(9), 779-794.

Kim, J. Y., \& Sung, K.-T. (2003). Marital violence among Korean elderly couples: A cultural residue. Journal of Elder Abuse \& Neglect, 13(4), 73-89.

Kyriakakis, S., Dawson, B. A., \& Edmond, T. (2012). Mexican immigrant survivors of intimate partner violence: Conceptualization and descriptions of abuse. Violence and Victims, 27(4), 548-562.

Lazenbatt, A., Devaney, J., \& Gildea, A. (2013). Older women living and coping with domestic violence. Community practitioner: the Journal of the Community Practitioners' \& Health Visitors' Association, 86(2), 28-32. 
Lee, E. (2007). Domestic violence and risk factors among Korean immigrant women in the United States. Journal of Family Violence, 22(3), 141-149.

Lowenstein, A., \& Ron, P. (1999). Tension and conflict factors in second marriages as causes of abuse between elderly spouses. Journal of Elder Abuse \& Neglect, 11(1), 23-45.

McFarlane, J., Hughes, R. B., Nosek, M. A., Groff, J. Y., Swedlend, N., \& Mullen, P. D. (2001). Abuse assessment screen-disability (AAS-D): Measuring frequency, type, and perpetrator of abuse toward women with physical disabilities. Journal of Women's Health and Gender-Based Medicine, 10(9), 861-866.

McGarry, J., Simpson, C., \& Hinchliff-Smith, K. (2011). The impact of domestic abuse for older women: A review of the literature. Health \& Social Care in The Community, 19(1), 3-14.

Messing, J. T., Amanor-Boadu, Y., Cavanaugh, C. E., Glass, N. E., \& Campbell, J. C. (2013). Culturally competent intimate partner violence risk assessment: Adapting the danger assessment for immigrant women. Social Work Research, 37(3), 263-275.

Mezey, N. J., Lori, A. P., \& Christopher, D. M. (2002). Redefining intimate partner violence: Women's experiences with physical violence and non-physical abuse by age. International Journal of Sociology and Social Policy, 22(7-8), 122-154.

Mitra, M., \& Mouradian, V. E. (2014). Intimate partner violence in the relationships of men with disabilities in the United States: Relative prevalence and health correlates. Journal of Interpersonal Violence, 29(17), 3150-3166.

Montero, I., Mariın-Baena, D., Escriba-Agüir, V., Ruiz-Pérez, I., VivesCases, C., \& \&Talavera, M. (2013). Intimate partner violence in older women in Spain: Prevalence, health consequences, and service utilization. Journal of Women \& Aging, 25(4), 358-371.

Montminy, L. (2011). Forms, manifestations and consequences of conjugal violence experienced by older women. International Journal of Victimology, 9(1), 281-293.

Montminy, L. (2005). Older women's experiences of psychological violence in their marital relationships. Journal of Gerontological Social Work, 46(2), 3-22.

Montminy, L., \& Drouin, C. (2009). Violence in a conjugal context among the elderly: A particular reality. Interdisciplinary research center on family violence and violence against women.

Morash, M., Bui, H., Zhang, Y., \& Holtfreter, K. (2007). Risk factors for abusive relationships: A study of Vietnamese American immigrant women. Violence Against Women, 13(7), 653-675.

Nosek, M. A., Foley, C. C., Hughes, R. B., \& Howland, C. A. (2001). Vulnerabilities for abuse among women with disabilities. Sexuality and Disability, 19(3), 177-189. 
Oxman-Martinez, J., \& Krane, J. (2005). A mismatch between theory and practice? Domestic violence and women from ethnic minorities. International Journal of Victimology, 3(3), $1-10$.

Plummer, S.-B., \& Findley, P. A. (2012). Women with disabilities' experience with physical and sexual abuse. Trauma, Violence, \& Abuse, 13(1), 15-29.

Raj, A., Silverman, J. G., McCleary-Sills, J., \& Liu, R. (2005). Immigration policies increase South Asian immigrant women's vulnerability to intimate partner violence. Journal of the American Medical Women's Association, 60(1), 26-32.

Rees, S, \& Pease, B. (2007). Domestic violence in refugee families in Australia: Rethinking settlement policy and practice. Journal of Immigrant and Refugee Studies, 5(2), 1-19.

Sabina, C., Cuevas, C. A., \& Zadnik, E. (2015). Intimate partner violence among Latino women: Rates and cultural correlates. Journal of Family Violence, 30(1), 35-47.

Sasseville, N., Maurice, P., Montminy, L., \& Hassan, G. (2017). Explanatory theories, risk factors and effective interventions with regard to domestic violence among seniors, the disabled and immigrants: Similarities and distinctions between these three contexts of vulnerability. Quebec: Society and Culture Research Fund.

Schröttle, M., \& Glammeier, S. (2013). Intimate partner violence against disabled women as a part of widespread victimization and discrimination over the lifetime: Evidence from a German representative study. International Journal of Conflict and Violence, 7(2), 232248.

Shah, S., Tsitsou, L., \& Woodin, S. (2016). Hidden voices: Disabled women's experiences of violence and support over the life course. Violence Against Women, 22(10), 1189-1210.

Sinha, M. (2012). Victimization in immigrant and visible minority populations. Public Health Agency of Canada. Sinha, M. (2013). Measuring violence against women: statistical trends (Statistics Canada Catalog No. 85-002-X).

Statistics Canada. Smith, D. L. (2008). Disability, gender and intimate partner violence: Relationships from the behavioral risk factor surveillance system. Sexuality and Disability, 26(1), 15-28.

Sormanti, D. M., Wu, E., \& El-Bassel, N. (2004). Considering HIV risk and intimate partner violence among older women of color: A descriptive analysis. Women \& Health, 39(1), 45-63.

Sormanti, M., \& Shibusawa, T. (2008). Intimate partner violence among midlife and older women: a descriptive analysis of women seeking medical services. Health \& Social Work, 33(1), 33-41.

Stöckl, H., \& Penhale, B. (2015). Intimate partner violence and its association with physical and mental health symptoms among older women in Germany. Journal of Interpersonal Violence, 30(17), 3089-3111. 
Stöckl, H., Watts, C., \& Penhale, B. (2012). Intimate partner violence against older women in Germany: Prevalence and associated factors. Journal of Interpersonal Violence, 27(13), 2545-2564.

Teaster, P. B., Roberto, K. A., \& Dugar, T. A. (2006). Intimate partner violence of rural aging women. Family Relations, 55(5), 636-648.

Vives-Cases, C., Gil-González, D., Ruiz-Pérez, I., Escribà-Agüir, V., Plazaola-Castanõ, J., Montero-Pinãr, M. I., \& Torrubiano-Domínguez, J. (2010). Identifying sociodemographic differences in intimate partner violence among immigrant and native women in Spain: A cross-sectional study. Preventive Medicine: An International Journal Devoted to Practice and Theory, 51(1), 85-87. 12

Vives-Cases, C., Torrubiano-Domínguez, J., Gil-González, D., La Parra, D., Agudelo-Suárez, A., Davó, M. C., Pérez-Belda, M. C., \& Martínez-Román, A. (2013). Social and immigration factors in intimate partner violence among Ecuadorians, Moroccans and Romanians living in Spain. European Journal of Public Health, 24(4), 605-612.

World Health Organization. (2013). Violence against women: Action in the health sector. World Health Organization.

Yon, Y., Wister, A. V., Mitchell, B., \& Gutman, G. (2014). A national comparison of spousal abuse in mid- and old age. Journal of Elder Abuse \& Neglect, 26(1), 80-105.

Zannettino, L. (2012). "There is no war here; it is only the relationship that makes us scared": Factors having an impact on domestic violence in Liberian refugee communities in South Australia. Violence Against Women, 18(7), 807-828.

\section{Author Biographies}

Nathalie Sasseville, $\mathrm{PhD}$, is a professor in the School of Social Work at Université du Québec à Chicoutimi in Quebec. Her research is focused on women who are vulnerable to intimate violence, such as women with disabilities, elderly women, and immigrant women. She also interested in improving practices addressed for these groups of women.

Pierre Maurice is involved in the "Safety, Violence and Injury Prevention" team at the Quebec National Institute of Public Health. He is also a clinical professor at Laval University and the director of the Quebec WHO Collaborating Center for Safety Promotion and Injury Prevention. He has been leading a team aimed at promoting safety and preventing violence in Quebec such as domestic violence.

Lise Montminy is an associate professor at the Université de Montréal's School of Social Work. She is interested in the issues of elder domestic violence and family violence in an aboriginal context. Between 2006 and 2017, she headed the School of Social Work and the Centre de recherche interdisciplinaire sur la violence familiale et la violence faite aux femmes at Université de Montréal. 
Ghayda Hassan is a psychologist and professor of clinical psychology at UQAM in Montreal. She is the director of the Canadian Practitioner Network for the Prevention of Radicalization and Extremist Violence. She is UNESCO-PREV Cochair (Prevention of Radicalization and Extremist Violence). Her systematic reviews, research, and clinical activities are centered on intervention in family violence and cultural diversity, especially working with vulnerable immigrants and refugees.

Emilie St-Pierre is an MA candidate in social work at Université du Québec à Chicoutimi in Quebec. She is currently working as a research assistant and as a teaching assistant at the Teaching Social Work Unit at UQAC. Her main focuses of research are concerning intimate violence, the educational trajectories of aboriginal students, and the consequences of anxiety disorders on the school path of university students. 